\title{
a PERSONAGEM NO ROMANCE MODERNo *
}

Oscar Tacca $* *$

Poder-se-ia dizer que a história do romance moderno é a história das suas personagens. Poucas perspectivas apresentam uma convergência mais nitida e reveladora de fundo e forma. Com efeito, ninguém ignora o papel cminentemente instrumental que desempenha a personagem. $\mathrm{E}$ ninguém ignora também que ć nelas que vive o romance. Sem separar ambos os conceitos (fundo e forma) como fazia a antiga preceptiva, sem identificá-los fazendo de ambos uma coisa única, como abusivamente pretendia o intuicionismo croceano, é evidente que através do diferente tratamento da personagem se foi acrescentado a riqueza cambiante deste gênero voraz. Ou dito em linguagem mais habitual e didática: cada novo conteúdo exigiu novas formas, sendo entre estas a relação autor-personagem (autonomia, identificação, rebeldia, distância, procura. conflito. catarse) a que, de modo mais eficaz permitiu ir instaurando em cada caso essa diferente explicação, apresentaçāo ou correção do mundo e da vida que é o romance.

Se esta não é, como se disse, nem o que acontece na alma do autor (lirica) nem o que acontece a outras personagens (teatro) senão essencialmentc a reação de certos seres frente a determinados acontecimentos, resulta claro o papel ao mesmo tempo subsidiário e capital da personagem. Subsidiário, enquanto a dita personagem poderá ser igualmente valente e covarde, sábio ou idiota, um herói ou um trapaceiro. Capital, enquanto o romance nāo for senão esse espelho-consciência que se detém em um caminho.

Durante todo o século XIX o autor utilizou-se da personagem para mostrar algumas açōes ou acontecimentos excepcionais, que exigiam de alguma nraneira seres excepcionais. Todas as personagens de Balzac são pessoas de exceção. Ainda em sua insignificância, excepcionais eram as ocorrências de Madame Bovary e de Rojo y Negro, extraídos da crônica policial. Persona-

- Traduzido do Espanhol por Nair Nodoca Takeuchi, Auxiliar de Ensino de Língua Espanhola no Departamento de Letras Estrangeiras Modernas da Universidade Federal do Paraná.

* Professor de Teoria Literária, Oscar Tacca è autor de vários trabalhos entre os quais se destacam Ia Historia Literaria (Madrid, Gredos, 1968, 204 p.) e Las voces de la novela (Madrid, Gredos, 1973, 205, p.). Atualmente, exerce também. as funções de Diretor do Instituto de Letras da Facultad de Fumanidades de la Universidad Nacional del Nordeste em Resistencia, Argentina. 
gem foi sinônimo do herói e anti-herói. Igual prestígio para o bem c para o mal. Don Quijotc e Lázaro. Papá Goriot e Julien Sorel. O autor encarnou cm sua personagem uma consciência universal. E a encarnou concreta e minuciosamente. O velho Grandet:

cra um homem de uns cinco pés, rechonchudo, quadrado, com a barriga das pernas de doze polegadas de circunferência. com joelhos avultados e largos ombros; seu rosto era redondo, curtido, marcado de variola; queixo reto, lábios sem sinuosidade, dentes brancos, seus olhos tinham a expressão calma e fascinante que o povo atribui ao basilisco; em sua testa, cheia de rugas transversais, não faltavam protuberâncias significativas; seus cabelos amarelos e grisalhos eram branco e ouro. seu nariz, largo na ponta, tinha uma verruga cheia de malícia. 1

A encarnação adquire em Balzac a convicção de uma tcoria: a fislonomia, amplamente exposta pelo autor. A minúcia e a precisão no trajar fazem falar hoje de vestinomonia. Consequiência natural: o retrato. Balzac é o maior retratista de todos os tempos. A Comédia Humana não é senão uma imensa "galeria". A personagem, foi, pois, durante o século XIX o que o autor quis que fosse: um exemplo; ou melhor, como dizem os biólogos, um exemplar. Encarregado de exemplificar. O autor o trouxe à cena: fê-lo passcar, fê-lo cizer, fê-lo fazer. Quando alguém lhe perguntava por ela, dizia orgulhoso: "Madame Bovary? C'est moi". E ia-se, para voltar com outro disfarce.

A personagem foi pois um "moi, um eu, ao que - por isso mesmo - convinha respeitar. Dotado de vida, de energia, de arbítrio, suas açōes foram (como na vida) imprevisíveis. Tipo, mas não "caso".

Julián Marias distinguia, todavia, num artigo sobre Galdós, entre personagem e tipo (ou caso), exemplificando com felicidade: tipo ou caso é Robinson, o herói que sem a ilha, o papagaio, a bíblia, se desvanece; personagens são Don Quijote. Hamlet, porque ambos, longe de La Mancha ou de Elsinor, continuam sendo o que são. Mas convém separar ainda tipo e caso, universal e livre o primeiro, mais particular e determinado o segundo. Robert Ricatte diferencia em seu livro sobre os Goncourt personagens-mito. personagens-destino e personagens-caso, destacando para os últimos "o casáter excepcional $\mathrm{e}$ individual de suas paixōes inveteradas". 2

Caso, e mesmo "caso clínico", foi o que fez da personagem o autor naturalista. Com o romance experimental, um rigoroso determinismo tira-lhe toda a liberdade. A personagem deixa de ser uma mostra, para ser uma prova. Vemos desde o princípio que Coupeau vai terminar na morte e no alcoolismo, Gervaise 3 na prostituição. Destino inelutável cumprindo inexora-

1 BALZAC, H. Eugénie Grandet. Paris, Garnier, 1966. p. 19.

2 RICATTE, Robert. La création romanesque chez les Goncourt. Paris, A. Colin, 1953.

3 ZOLA, Emile. LAssomoir. Paris, Fasquelle, 1971. 495 p. 
velmente as leis da herança, o álcool, a miséria, Destino nāo muito difcrente co que cumpre, $\mathrm{cm}$ definitivo, a personagem do romance de tese: emissário do autor, sacerdote, testa-de-ferro, alcoviteiro e mártir do romancista, encarregado de consumar, ou de que nele se consumam os desejos daquele. Faul Bourget e 0 Discípulo. Adrien Sixte: e Robert Greslou, ambos corroborando Q.E.D., como costumam terminar os teoremas.

Os primeiros anos do nosso século viram nascer uma personagem difeıentc: Lafcádio, ${ }^{4}$ parente próximo, definitivamente, de todos os heróis do romance psicológico, e ainda, do romance sensual de Colette. Uns e outros fázem suas experiências em contacto com os alimentos terrestres. Heróis que vivem a vida como uma aventura apaixonante, às vezes jubilosos, que sc introspeccionam. que se definem na sua mais absoluta singularidade.

Mas Lafcádio, "chegado à sua maturidade, e tendo abandonado as vacilaçōes encantadoras do adolescente gidiano, se fazia conqulstador do mundo e amante de virtudes brutals" (Albérès). Nasce o compromisso. Pelo menos uma forma de compromisso. O compromisso ético. De um lado, a personagem desgarrada de Mauriac e Bernanos. Do outro, a personagem aventureira de Lawrence, Malraux. Saint-Exupcry. O romancista submete a personagem a um dramático confronto com o mal ou com a açāo. A consciência nasce da ação e não ao contrário, diz Malraux. O bem se gera muitas vezes no mal, diz por seu lado Mauriac. O romancista decanta sua experiência no romance. Volta a viver por procuraçāo

O conceito do homem já variou. Já nāo se pensa que este se define em sua mais estrita individualidade, em seu isolamento, em seu retiro, longe de todo móvel prático ou utilitário. Os romancistas da ação acreditam, ao contrário, que o homem não se conhece a si mesmo na solidão, mas em contacto com os outros homens. O homem só é uma enteléquia. De nada vale contemplar-me e definir-me a sós como valente. franco e generoso, se a açāo prova que sou egoísta. falso e covarde. A introspecção psicológica é uma ancestral forma de engano. O homem não é o que diz, mas o que faz. Não $s \in$ define de dentro, mas de fora.

Daí ao romance americano da década de quarenta, um só passo. A persnnagem é representada através da sua conduta, do seu comportamento. Behaviorismo, que Claude-Edmonde Magny define como "um part1-prls de considerar real, na vida psicológica de um homem ou de um animal, somente aquilo que poderia perceber um observador puramente exterior, representado em última instância pela objetiva de uma câmara fotográfica". O romance rhegará a ser "o conto de um Idiota cheio de ruído e de fúria, sem significado" (Faulkner).

4 GIDE, Andre. Les caves du Vatican. Paris, Gallimard, 1970. 253 p. 
Em nosso tempo, o autor tem se distanciado mais de sua personagem, dessa personagem que foi incorrendo $\mathrm{cm}$ rebelião primeiro, $\mathrm{cm}$ desacato depois, em tirania finalmente: tem-lhe tirado, pouco a pouco, quase tudo: inteligência, coragem, prestigio, beleza, dinheiro. Até lhe tem usurpado a céclula de identidade, deixando-o em precária condição legal, com um nome sem sobrenome, com um sobrenome sem o nome, com um mote, um apelido ou um inicial: K, Eróstrato, o Anão. Não satisfeito com o despojo de seus bens tradicionais, o angustia, o persegue, o acurrala. A longa série de acossados prova ao mesmo tempo a constância e a diversidade do fato: acossamento físico e policial $\mathrm{cm}$ o Terceiro Homem de Graham Greene, político em o Zero e o Infinito de Koestler, psicológico e moral em Pascual Duarte de Cela, metafísico em Eróstrato de Sartre e 0 Estrangeiro de Camus, religioso em Barrabás de Pär Lagerquist. E não só está o homem acossado, mas a tnulher tambćm: a Adriana Mesurat de Julien Green, a Cecilia de Bonjour Tristesse (Françoise Sagan).

Mas o romancista não sō persegue, fustiga e aparta a personagem, como também a processa. Este é o sintoma que define toda uma novelística de pré-guerra e pós-guerra. Para isso, recorre tanto à minuciosa retícula da Justiça como ao aparelho tosco, grosseiro e abusivo da lel.

O simples número dos processados mostra por si que o romance do nosso tempo deixou de ser o laboratório experimental dos naturalistas, o parque de diversões de Lafcádio, o grande teatro do mundo de Proust, o campo de desportos de Saint-Exupéry e Malraux, para passar a ser uma grande sala de audiências na qual o leitor é o público, a personagem no banquinho e o autor é o juiz, às vezes só o escrivão, quase nunca o defensor, amiúde o fiscal. Uma longa série de acusados aguarda seu turno em calabouços úmidos e mal cheirosos: José K (El processo de Kafka), Macías (Cara a la muerte de Emmanuel Robles), Meursault (EI extranjero de Camus), Pablo Ibbieta El muro de Sartre), Pascual Duarte (La familia de Pascual Duarte de Camilo J. Cela), el cura Juan (El poder y la gloria de Graham Greene), Rubashov (El cero y el infinito de Arthour Koestler), Barrabás (Barrabás de Pär Lageskvist)...

Fato curioso: entre eles não há valentes, e - mais curioso ainda ninguém é inocente. Mas, - paradoxalmente, e para dizê-lo com palavras de Kafka em O Processo - nem todos têm culpa: "os acusados são, precisamente, os mais belos; não pode ser a sua falta o que os embeleza, pois nem todos eles sāo culpados". E não há fuga. Nem há indulto. Todos, por igual, condenados à morte. Desde José $\mathrm{K}$ a quem afincam três vezes a faca e que exclama: - Como um cão! ("era como se a vergonha devesse sobreviver-lhe") até Rubashov, com um tiro na nuca, outro na orelha, acolhido por um rumor de mar "como um encolhimento de ombros da eternidade"; desde Meursault, que só deseja muitos espectadores e gritos de ódio na cxecução, até o padre Juan, que pergunta quanto dura um segundo de dor, 
e cai crivado por uma dúzia de balas; desde Pascual Duarte, que "terminou seus dias cuspindo e esperneando, sem cuidado nenhum dos circunstantes, e da maneira pior e mais baixa que um homem possa terminar; demonstrando a todos seu medo à morte" até Barrabás que "sentindo chegar a morte, a que tanto temera, disse entre as trevas, como se a elas falasse: - A ti encomendo meu espírito. E entregou sua alma".

Mas um novo assédio aguardava a personagem. Quando menos esperava, em pleno sol e à hora da sesta, quando ia radiante de sensaçōes e vazio de "psicologia", na virada de uma esquina absurda é assaltada para o despojo do pouco que the restava. Já não resiste, nem cospe, nem blasfema. 0 escritor do romance objetivo deixou de acreditar na personagem. Sabe que a era da dupla suspeita começou, segundo o denunciara Nathalie Sarraute: desconfiança do leitor com respeito ao autor, desconfiança do autor com respeito ao leitor.

A personagem já não se olha, propriamente, nem de dentro nem de fora. Busca, ele mesmo (ou seja de dentro) ver-se a si mesmo (ou seja de fora). Mas, claro está, já não crê nos espelhos. Procura ver-se - como Mathias, 5 nas coisas que o obsessionam: na forma do oito repetida, no pejaço de corda, no olho da gaivota. Fala, mas é como se falasse o polícia que o segue. A personagem deixa de ser um caráter, um documento-limite. A "personalidade" se dilui em uma série de estados psicológicos, cambiantes, contraditórios, escorregadiços. Um homem nāo é um carater, nem, menos alnda, uma história, nem um conjunto de hábitos: é o vai-vem incessante e brando entre o particular e o geral, disse Sartre 6 a propósito de Nathalie Sarraute.

Para o ponto de vista tradicional, quase todos os protagonistas do romance objetivo parecem personagens secundários. O culto exclusivo do "humano" deixou lugar a uma tomada de consciêncla mals vasta, menos antropocêntrica. 7

A personagem, é claro, não é tudo no romance. Mas sua trajetória reyela com especial nitidez a do gênero. E através da diferente revelação dialética autor-personagem-leitor que o romance muda de forma e sentido. Não há perigo de anemia ou empobrecimento neste enfoque, uma vez que as personagens não sāo uma cadeia independente da vida, nāo se engendram €m si mesmos. Dito de outra maneira: as personagens nāo têm descendência. Se declarados (como Esplandián. filho de Amadís de Gaula), os descendentes são fracos, se extinguem. Se adúlteros (como os Lázaros), pior.

5 ROBBE-GRILLET, Alain. Le voyeur. Paris, Ed. de Minuit, 1959, 255 p.

6 SARTRE, J. P. Préface. In: SARRAUTE, Nathalie. Portrait d'un inconnu. Paris, Union Générale d'Editions, 1956. p. 13.

7 ROBBE-GrILIET, Alain. Pour un nouveau roman. Paris, Gallimard, 1964. p. 33.

Letras, Curitiba (25) : $193-299$, jul. 1976 
As personagens são como os anōes, uma raça criada pelos homens. Podem dizer também, como 0 Anão de Lagerqvist, substituindo anōes por persosagens:

Nós os personagens não geramos filhos, pois somos estéreis. Não nos ocupamos em perpetuar a vida, nem tampouco o desejamos. E não necessitamos ser fecundos porque a própria espécie humana produz suas personagens; nẫo há, pois, que preocupar-se com isso. Deixamos que nos gerem essas orgulhosas criaturas, $c$ que tenham as dores do parto, que são as mesmas para todos. Nossa raça se perpetua constantemente através das outras, e é assim, e não de outro modo. como viemos a este mundo. Esta é a razăo profunda da nossa esterilidade. Conseqüentemente, pertencemos e não pertencemos a nossa raça. Somos hóspedes de visita. Antigos hóspedes cheios de rugas cuja visita se prolonga há milhares de anos. 8

\section{REFERENCIAS BIBLIOGRAFICAS}

BALZAC, H. Eugenie Grandet. Paris, Garnier, 1966. 373 p.

GIDE, André. Les caves du Vatican. Paris, Gallimard, 1970. $253 \mathrm{p}$.

LAGERKVIST, Pär. El enano. Buenos Aires, Emece, 1964. 181 p.

RICATTE, Robert. La création romanesque chez les Goncourt. Paris. A. Colin, 1953. ROBBE-GRILLET, Alain. Pour un nouveau roman. Paris, Gallimard, 1964. 183 p. - Le voyeur. Paris, Ed. de Minuit, 1959. $255 \mathrm{p}$.

SARRAUTE, Nathalie. Portrait d'un inconnu. Paris, Union Générale d'ditions, 1956. $243 \mathrm{p}$.

LOLA, Emile. Lassomoir. Paris, Fasquelle, 1971. $495 \mathrm{p}$.

\section{Resumo}

Poder-se-ia dizer que a história do romance moderno é a história das suas personagens. A personagem do século XIX era sinónimo de herói e anti-herói. A encarnação da consciência universal nas personagens de Balzac adquire a convicçāo de uma teoria: a fisionomia. Balzac é o maior retratista dc todos os tempos.

No romance naturalista a personagem era uma mostra, ou até uma prova, como o era no romance de tese: emissário do autor, sacerdote, testa-de- Herro, aucoviteiro e mártir do romancista. Personagem diferente nascida no início do século: Lafcádio. O romancista volta a viver por procuração.

Em nossos dias o autor tem se distanciado de sua personagem. Surge uma longa série de acossados, de processados.

A personagem nāo é tudo, mas sua trajetória revela com especial nitidez a gênero do romance.

\section{Resumen}

Podría decirse que la historia de la novela moderna es la historia de sus personajes. El personaje del siglo XIX era sinónimo de héroe $\mathrm{y}$ antihéroe.

8 LAGERKVIST, Pär. El enano. Buenos Aires, Emecé, 1964. p. 78. 
La encarnación de la consciencia universal en los personajes de Balzac adquicre la convicción de una teoria: la fisiognomonía. Balzac es el más grande retratista de todos los tiempos.

En la novela naturalista el personaje era una muestra, o hasta una prueba, como lo era en la novela de tesis: emisario del autor, vicario, tesraferro. alcahuete y mártir del novelista. Personaje diferente nacido en el inicio del siglo: Lafcadio. El novelista vuelve a vivir por procuración.

En nuestros dias el autor ha tomado mayor distancia de sus personajes. Surge una larga serie de acosados, de procesados.

El personaje no es todo, pero su trayectoria revela con especial nitidez el género de la novela. 